\title{
Periodontal Ligament Stem Cells
}

\author{
Hidefumi Maeda, Naohisa Wada, Shinsuke Fujii, \\ Atsushi Tomokiyo and Akifumi Akamine \\ Department of Endodontology \& Operative Dentistry, Kyushu University \\ Japan
}

\section{Introduction}

Millions of people experience consequential tooth loss related to irretrievable damage of the periodontium caused by deep caries, severe periodontal diseases or irreversible trauma, resulting in a decreased quality of life. Hence, dental scientists have focused much attention on tissue engineering techniques in an effort to address this condition. The periodontium is composed mainly of two soft tissues and two hard tissues; the former includes the periodontal ligament (PDL) tissue and gingival tissue, and the latter includes alveolar bone and cementum covering the tooth root. In particular, PDL is a dynamic connective tissue that is subjected to continual adaptation to maintain tissue size and width, as well as structural integrity, including fibers and bone modeling. The main role of PDL is to anchor the tooth root to the alveolar bone socket tightly, cushioning mechanical load that proceeds from mastication. Thus, PDL tissue constitutes the bedrock of periodontium to determine the life-span of tooth. In this chapter, we describe the phenotypes of multipotent clonal human PDL progenitor/stem cell lines that we have recently established, and present a comparison with PDL stem cells (PDLSCs).

PDLSCs represent typical properties of bone marrow-derived mesenchymal stem cells (BMMSCs). PDLSCs exhibit a self-renewing capacity and express cell surface markers similar to BMMSCs. PDLSCs also possess the multipotential to differentiate into various types of cells, such as osteoblast-like cells, adipocytes, chondrocytes and neurocytes, in vitro. Additionally, PDLSCs represent a distinctive potential to form cementum- and PDL-like tissues in vivo, suggesting that PDLSCs might belong to a unique population of somatic stem cells.

Since a very small number of stem cells are included in PDL tissue, researchers have tried to establish immortalized PDL stem cell lines for the convenience and consistency of analyses. Recently, we succeeded in establishing two clonal human PDL cell lines with multipotential by transduction with Simian Virus (SV) 40 large T-antigen and human telomerase reverse transcriptase. These clonal cell lines exhibited unique characteristics: cell line 1-11 demonstrated osteoblastic and adipocytic differentiation capabilities, and cell line 1-17 exhibited the potential to differentiate into osteoblasts, adipocytes, chondrocytes and neurocytes. Flow cytometric analysis demonstrated that the percentage of cells expressing BMMSC markers was very high in both cell lines. On the other hand, cell line 1-17 expressed embryonic stem (ES) cell marker genes at higher levels, compared with cell line 1-11. Furthermore, both cell lines expressed PDL phenotype-related molecules at equivalent levels while BMMSCs showed little expression. When transplanted into PDL defects formed 
in immunodeficient rats, cell line 1-11 homed on the surface of bone and cementum, and between bone and cementum, while cell line 1-17 was localized only between bone and cementum. Thus, we believe that both cell lines met the prerequisite for PDL stem cells, and furthermore, that the differentiation stage of cell line 1-17 may be more immature than that of cell line 1-11.

Differential analyses between these two clones will allow us to further reveal the mechanism of differentiation of PDL stem cells, as well as to elucidate key signals to direct stem cells, including other MSCs, induced pluripotent stem (iPS) cells or ES cells, toward the PDLlineage.

\section{What is the origin of PDL?}

PDL tissue originates from cranial neural crest (CNC)-derived ectomesenchymal cells (Chai et al., 2000). Neural crest cells are multipotent cell populations derived from the dorsal surface of the neural tube and migrate extensively during early stages of embryogenesis (Bronner-Fraser, 1993). The neural crest is divided into four specific regions that include the $\mathrm{CNC}$, trunk neural crest, vagal and sacral neural crest, and cardiac neural crest, depending on the crest cell potentials to develop into particular tissues. During craniofacial development, $\mathrm{CNC}$ cells migrate ventrolaterally and contribute significantly to the formation of mesenchymal structures in the head and neck (Le et al., 1993). When tooth development begins, the primitive oral epithelium thickens and proliferates into the underlying CNC-derived ectomesenchyme, promoting mesenchymal cellular condensation. The dental follicle (DF) derived from CNC (Chai et al., 2000) is a sac including these structures, namely the odontogenic organ during tooth germ development (Cho et al., 2000). DF cells differentiate into PDL cells and are also believed to contain the progenitor cells that differentiate into cementoblasts and osteoblasts (Ten Cate, 2008). Thus, the DF plays a crucial role in forming the PDL tissue, namely the fabrication of the periodontium.

\section{What are PDL tissues and what are their roles?}

PDL tissue is a major constituent of the periodontium, along with other components, such as gingival soft tissue, the cementum covering the tooth root and alveolar bone (Melcher, 1984). PDL tissue is a dynamic soft connective tissue that is situated between the tooth root and the bone socket, and the width of PDL tissue ranges from 0.15 to $0.38 \mu \mathrm{m}$ (Ten Cate, 2008). PDL tissue is composed of heterogeneous cell populations, various fibers, noncollagenous extracellular matrix (ECM) proteins, nerve fibers and blood vessels. PDL cell populations include fibroblasts, which are principal cells in PDL tissue (Berkovitz et al., 1995; Beertsen et al., 1997), undifferentiated mesenchymal cells, epithelial cell rests of Malassez and endothelial cells.

PDL cells not only produce collagen fibers and other ECM proteins, but have osteoblastic/cementoblastic properties (Roberts et al., 1982; McCulloch et al., 1991), such as high alkaline phosphatase (ALP) activity (Lekic et al., 1996) and the expression of osteoblastrelated genes, including Runt-related transcription factor-2 (Fujii et al., 2006), Osterix (Kato et al., 2005), bone sialoprotein (Lekic et al., 2001), osteopontin (Chutivongse et al., 2005), osteocalcin (Li et al., 2001) and periostin (Yamada et al., 2001). Additionally, PDL cells synthesize an osteoclastogenesis activator, receptor activator of NF-kappa B ligand (Kanzaki et al., 2001), as well as its inhibitor, osteoprotegerin (Wada et al., 2001; Hasegawa et al., 2002), suggesting that these cells participate in alveolar bone metabolism. 
The fibers in PDL tissues mainly comprise collagens and elastic system fibers. The predominant collagen in PDL tissue is type I collagen, and other collagens (types III, VI and XII) are also deposited in PDL tissue (Lukinmaa et al., 1992; MacNeil et al., 1998). The collagen fibers in PDL tissue form in definite and distinct bundles; the terminus of the principal collagen bundles insert into the cementum and alveolar bone, as known as Sharpey's fibers. Oxytalan fibers, a member of the elastic system fibers, are present within PDL tissue (Beertsen et al., 1997). The fibers run vertically along the cementum surface of the apical root, forming a three-dimensional branching meshwork that surrounds the roots (Ten Cate, 2008). PDL tissue plays a crucial role in fixing the tooth to the alveolar bone socket through these threedimensional structures, which involve cushioning mechanical loads such as compressive and tensile forces that proceed from mastication, as well as adjusting occlusal forces depending on food hardness via sensory nerve perception in the PDL tissue. Thus, PDL tissue constitutes the bedrock of periodontium, which determines the life-span of tooth.

Proteoglycans (PGs), including biglycan, CD44, decorin, fibromodulin, perlecan and versican are also present in PDL tissue as non-collagenous ECM proteins (Häkkinen et al., 1993; Cheng et al., 1999). PGs are extracellular and cell surface-associated macromolecules that regulate cell adhesion, cell growth, matrix formation and bind growth factors.

\section{What causes PDL tissue loss?}

PDL tissue loss is caused mainly by the inflammatory or physical tissue destruction stimulated by severe periodontitis, deep caries reaching infrabony levels or irreversible trauma. Bacterial infection is essential for the initiation of periodontitis. One of the components of the cell wall of gram-negative anaerobic bacteria, lipopolysaccharide, which is a complex glycolipid (Lamont et al., 1998), promotes the expression of pro-inflammatory cytokines, such as interleukin-1 beta and tumor necrosis factor-alpha, in macrophages and PDL cells (Lindemann et al., 1988; Wada et al., 2004). These cytokines are reported not only to disturb the function of PDL cells (Quintero et al., 1995; Agarwal et al., 1998), but also to stimulate the production of matrix metalloproteases (MMPs), such as MMP-1, in PDL cells (Oyama et al., 2007; Xiang et al., 2009). MMP-1 is the major proteolytic enzyme that can cleave native type I and type III collagens, suggesting its aggressive contribution to the destruction of the PDL structure (Birkedal-Hansen, 1993).

\section{What is needed for the regeneration of PDL tissues?}

To create effective and practical therapies for the defects of PDL tissue, new approaches based on tissue engineering concepts have been developing. Tissue engineering, first described in the late 1980s, is an emerging interdisciplinary field in biomedical engineering. This concept aims to create or regenerate functional tissues through the use of an appropriate combination of three fundamental tools, namely signaling molecules, engineering scaffolds and cells, which together are also known as the tissue engineering triad (Langer \& Vacanti, 1993). In addition to these triads, we think that blood supply and the innervation of peripheral nerves are requisites in PDL tissue regeneration.

\subsection{Signaling molecules}

Several growth factors have been reported to promote the regeneration of PDL tissue in vitro and in vivo. Growth factors are natural biological molecules that bind to cell-surface 
receptors and regulate key cellular activities during tissue repair, including cell proliferation, chemotaxis, differentiation and matrix synthesis (Chen et al., 2010a).

\subsubsection{Basic Fibroblast Growth Factor}

Basic fibroblast growth factor (bFGF) is a single-chain polypeptide mainly associated with mesoderm- and neuroectoderm-derived cells, and belongs to a member of the heparinbinding growth factor family (Gospodarowicz et al., 1986). bFGF is involved in controlling cell proliferation, migration, differentiation and survival, and also has a role in angiogenesis (Savona et al., 1997). In PDL cells, bFGF has been shown to increase proliferation, the production of hyaluronan, heparan sulfate and osteopontin, and the expressions of MMP-1, MMP-3 and MMP-9 mRNA, while inhibiting the induction of ALP activity, mineralized nodule formation and the expressions of ALP, type I collagen, MMP-2 and tropoelastin mRNA (Takayama et al., 1997; Palmon et al., 2001; Shimabukuro et al., 2008; Terashima et al., 2008; Hakki et al., 2009). Additionally, the topical application of bFGF was shown to significantly induce PDL regeneration without ankylosis, root resorption and epithelial down-growth in an experimental alveolar bone defect model in dogs (Murakami et al., 2003). Moreover, the regenerative effect of bFGF on PDL tissue in patients with periodontitis was confirmed in a randomized controlled phase II clinical trial and a multi-center randomized clinical trial (Kitamura et al., 2011).

\subsubsection{Transforming Growth Factor}

Transforming growth factor- $\beta$ (TGF- $\beta$ ) consists of three $25-\mathrm{kDa}$ homodimeric mammalian isoforms ( $\beta 1, \beta 2$ and $\beta 3)$. TGF- $\beta 1$ plays an important role in wound healing and repair through the induction of angiogenesis, the increase of ECM formation and the inhibition of inflammation and matrix degradation in mesenchymal cells (Ling \& Robinson, 2002). In PDL cells, TGF- $\beta 1$ has been reported to increase cell-surface proteoglycan genes such as syndecan-2 and betaglycan (Worapamorn et al., 2001), and has been reported to promote the synthesis of DNA, fibronectin, secreted protein acidic and rich in cytokine/osteonectin (SPARC), and connective tissue growth factor (CTGF) (Fujita et al., 2004; Takeuchi et al., 2009). Previous reports have demonstrated the opposite effects of TGF- $\beta 1$ on PDL cells: Si \& Liu (2001) have shown a significant increase of ALP activity, while Brady et al. (1998) reported ALP suppression. Importantly, Fujii et al. (2010) reported the contrastive effects of TGF- $\beta 1$ on primary PDL cells and a PDL stem/progenitor cell line: TGF- $\beta 1$ promoted proliferation and showed no alternation of alpha-smooth muscle actin, type I collagen and fibrillin 1 mRNA expressions in primary PDL cells, whereas TGF- $\beta 1$ suppressed proliferation and up-regulated these mRNA expressions in a PDL stem/progenitor cell line. These results suggest the dual effects of TGF- $\beta 1$ on PDL cells depending on their differentiation stage.

\subsubsection{Bone Morphogenetic Protein}

Bone morphogenetic proteins (BMPs) and growth and differentiation factors (GDFs) together form a single family of cystine-knot cytokines in the TGF- $\beta$ superfamily. A feature of the BMPs is their ability to induce bone formation and regulate morphogenetic activities in the development of various tissues. Many reports have demonstrated the promotion of alveolar bone and cementum regeneration by BMP-2 in several experimental periodontal defects (Kinoshita et al., 1997). Unfortunately, BMP-2 treatment did not induce the 
formation of functional PDL structures, such as Sharpey's fibers, and sometimes elicited ankylosis (Selvig et al., 2002). Osteogenic protein-1 (OP-1/BMP-7) promoted ALP activity and osteocalcin expression in PDL cells (Dereka et al., 2009). Moreover, OP-1-treated PDL precursor cells increased proliferation (Rajshankar et al., 1998). In vivo assays with OP-1 treatment have demonstrated the stimulation of osteogenesis, cementogenesis and new attachment formation in Class III furcation defects (Giannobile et al., 1998). BMP-12 has been reported to act as a signaling molecule during embryonic tendon, ligament and joint formation, and is reportedly involved in tendon and ligament healing (Wolfman et al., 1997). Wikesjö et al. (2004) demonstrated the promotion of new bone and cementum formation with BMP-12 treatment in supra-alveolar periodontal defects. Interestingly, they also showed that BMP-12 treatment induced to form functionally oriented PDL bridging the gaps between bone and cementum, whereas this was a rare observation in BMP-2 treatment. GDF-5, known as BMP-14, was reported to significantly induce formation of new bone, cementum and fibers along the root surface in one-wall intrabony defects without root resorption and ankylosis (Kim et al., 2009).

\subsubsection{Brain-Derived Neurotrophic Factor}

Brain-derived neurotrophic factor (BDNF) belongs to the second member of the neurotrophin family and is involved in differentiation, proliferation, survival, homeostasis and regeneration of central and peripheral neurons by binding to cell surface receptors TrkB and p75NTR (Ebendal, 1992). PDL cells have been reported to increase proliferation and the expressions of ALP and osteocalcin mRNA and osteopontin, BMP-2 and type I collagen synthesis through BDNF exposure (Tsuboi et al., 2001). Moreover, BDNF or BDNF/highmolecular-weight-hyaluronic acid reportedly increased the formation of new alveolar bone, cementum, Sharpey's fiber-like connective tissues and blood capillary in Class III furcation defects in a dog model (Takeda et al., 2005; Takeda et al., 2011).

\subsubsection{Connective Tissue Growth Factor}

Connective tissue growth factor (CTGF) is a cysteine-rich, matrix-associated, and heparinbinding protein that was originally discovered as a chemotactic and mitogenic factor for fibroblast-like cells in vitro (Bradham et al., 1991). After CTGF treatment, hMSCs revealed a typical fibroblastic phenotype and failed to show osteogenic or chondrogenic differentiation (Lee et al., 2006). CTGF stimulated proliferation, ALP, type I collagen, and periostin mRNA expression, ALP activity and collagen synthesis in PDL cells, while CTGF induced little change of osteopontin and osteocalcin mRNA expressions (Asano et al., 2005). Transplantation of CTGF-treated PDL progenitors exhibited an increase of type III collagen, biglycan and periostin mRNA expressions and enhanced the formation of PDL-like tissue, namely dense collagen fiber bundles with a high expression level of periostin in a mouse model (Dangaria et al., 2009).

\subsubsection{Wnt}

Wnts are a family of 19 secreted cysteine-rich glycoproteins that participate in embryonic development and adult homeostasis by regulating cellular proliferation, differentiation and apoptosis (Logan \& Nusse, 2004). Wnt proteins transduce multiple signaling cascades including the canonical Wnt/ $\beta$-catenin pathway, the Wnt/Ca2+ pathway and the Wnt/polarity pathway. Among those, canonical Wnt/ $\beta$-catenin has been reported to 
increase bone formation through the stimulation of osteoblast development and the inhibition of osteoblast and osteocyte apoptosis (Kato et al., 2002; Bodine et al., 2004). The canonical Wnt/ $\beta$-catenin pathway has been shown to promote mineralized nodule formation, ALP activity and osteogenic transcription factor expression in PDL cells (Heo et al., 2010), while the pathway reportedly suppressed ALP activity and cementum functionassociated gene expression in cementoblasts (Sodek \& Limeback, 1979).

\subsubsection{Platelet-Derived Growth Factor}

Platelet-derived growth factor (PDGF) is composed of two disulfide bounded polypeptide chains that are encoded by two different genes, PDGF-A and PDGF-B. In nature, PDGF can exist as a homodimer: PDGF-AA and PDGF-BB. PDGF-BB was reported to promote the proliferation, adhesion, type I collagen synthesis and migration of PDL cells (Belal et al., 2006), as well as to enhance periodontal regeneration of Class III furcation defects in beagle dogs without significant ankylosis or root resorption (Cho et al., 1995). Moreover, PDGF-BB has been shown to stimulate a significant increase in the rate of clinical attachment level gain and bone defect fill, as well as to reduce gingival recession (Nevins et al., 2005).

\subsubsection{Enamel Matrix Derivative}

Porcine enamel matrix protein was reported to induce new bone and cementum formation in periodontal defects in monkeys (Hammarstrom, 1997). Since then, many in vivo and in vitro studies, as well as clinical trials, have revealed the progression of PDL regeneration in the use of enamel matrix derivative (EMD). EMD has been shown to promote the growth, proliferation, migration, adhesion and protein synthesis of PDL fibroblasts, osteoblasts and cementoblasts, as well as to regulate their bone-related gene expressions (Carinci et al., 2006). Additionally, EMD has been shown to induce the production of several growth factors in PDL cells and osteoblasts (Mizutani et al., 2003; Heng et al., 2007).

\subsection{Scaffolds}

Scaffolds that have the capabilities of growth factor delivery, easy cellular infiltration and subsequent tissue integration become powerful tools for tissue engineering. PDL cells are subjected to a multitude of factors and microenvironments presented by local substrates and their surface conditions. There are two classes of scaffold biomaterials: natural materials and synthetic materials.

Of the natural materials, collagens are ubiquitous interstitial proteins responsible for maintaining structural integrity and are rapidly synthesized and degraded in PDL tissue (Sodek \& Limeback, 1979). Several reports have revealed the promotion of PDL regeneration using collagen gels incorporating BMP-2, as well as gelatin hydrogels containing bFGF (King et al., 1998; Nakahara et al., 2003).

Chitosan is a deacetylated derivative of chitin, the second most abundant natural polymer found in the shells of crustaceans (Kim et al., 2008). Chitosan has been shown to increase type I collagen and ALP mRNA expressions in PDL cells, and chitosan scaffolds have been reported to induce the formation of new bone and cementum in one-wall intrabony defects (Yeo et al., 2005; Pang et al., 2005). Additionally, chitosan scaffolds that release growth factors such as PDGF or bFGF have been shown to accelerate PDL regeneration (Inanç et al., 2007; Akman et al., 2010).

Calcium hydroxyapatite is a main component of root cementum and alveolar bone. PDL cells cultured with nanoparticles of hydroxyapatite have been reported to significantly 
increase proliferation and ALP activity (Sun et al., 2007), and porous hydroxyapatite scaffolds have induced pocket depth reduction and attachment gain in PDL tissue (Carraro, 1988). Moreover, numerous hybrid calcium hydroxyapatite scaffolds, including nanohydroxyapatite/chitosan (Zhang et al., 2007), nanohydroxyapatite/collagen (Fukui et al., 2008) and hydroxyapatite/gelatin components (Rungsiyanont et al., 2011) have shown promise for PDL tissue regeneration. GEM 21S ${ }^{\circledR}$, which consists of a combination of PDGF$\mathrm{BB}$ and $\beta$-tricalcium phosphate (TCP) matrix ranging in size from 250 to $1000 \mu \mathrm{m}$ ("small $\beta$ TCP"), has been used widely in the treatment of periodontitis.

Synthetic polymers have also been used as scaffold materials for tissue engineering. In particular, polyesters such as polyglycolic acid (PGA), polylactic acid (PLA) and polylacticcoglycolic acid (PLGA) have been frequently used for PDL regeneration (Chen et al., 2010b). Moreover, several reports have demonstrated the utility of the combination of growth factors and synthetic polymers such as GDF-5/PLGA (Kwon et al., 2010). Interestingly, Chen et al. revealed that BMP-2-loaded pellets incorporated into glycidyl methacrylated dextran/gelatin scaffolds stimulated not only bone and cementum formation, but also PDL-like connective tissue regeneration (Chen et al., 2007). Implantation of TGF- $\beta 3$ in lyophilized Matrigel ${ }^{\circledR}$ scaffolds in baboon Class III furcation defects with minced fragments of rectus abdominis muscle reportedly induced responding stem cells to stimulate the formation of large amounts of alveolar bone with associated PDL fibers and newly formed cementum (Ripamonti et al., 2009).

\subsection{Cells}

The use of stem cells as primary cell sources is of enormous interest to clinicians and researchers for their great potential in tissue engineering applications. Sources of stem cells from human (Feng et al., 2010) and swine (Ding et al., 2010) PDL tissues are reported to be the most potent for PDL tissue regeneration, as well as canine (Kawaguchi et al., 2004) and human (Yamada et al., 2006) bone marrow and rat adipose-tissue (Tobita et al., 2008). Recent studies have attempted topical applications of stem cells combined with growth factors and/or scaffolds for PDL tissue regeneration. Indeed, the combination of platelet-rich plasma with growth factors, fibrin scaffolds and BMMSCs successfully regenerated PDL tissue in a clinical setting (Yamada et al., 2006). Adipose-derived stem cells mixed with platelet-rich plasma promoted PDL regeneration in rat PDL tissue defects (Tobita et al., 2008). Moreover, the PDL cell population has been described to include stem/progenitor cells that have the possibility to repair destructed PDL tissues by recruiting their latent regenerative potential to differentiate into fibroblasts, osteoblasts or cementoblasts in response to their microenvironment (Melcher, 1976; McCulloch et al., 1987). Bovine derived bone substitute scaffolds mixed with fibrin were shown to represent high biological affinity and support for the growth, migration and differentiation of PDL stem cells (Trubiani et al., 2008). Collagen scaffolds were shown to stimulate PDL stem/progenitor cells to attach, proliferate, exhibit a PDL spindle-like morphology and subsequently form PDL-like tissue (Luan et al., 2009). BMP-2 stimulation was shown to induce mineralized nodule formation of multipotent PDL cells, while bFGF stimulation elicited capillary-like structure formations (Shirai et al., 2009). Hydroxyapatite/tricalcium phosphate blocks, into which stem cells from root apical papilla were loaded, when furthermore coated with Gelfoam containing PDL stem cells and implanted into extracted sockets, developed PDL-like tissue around the blocks (Sonoyama et al., 2006). These results suggest the efficacy of therapeutic approaches based on tissue engineering triads in PDL tissue regeneration. 


\subsection{Blood supply}

PDL tissues are nourished from supraperiosteal arterioles along the surface of alveolar bone, vessels of the PDL region and arterioles from the interdental septum extending into the gingival and sulcus area (Egelberg, 1967). Therefore, the lack of sufficient blood supply may restrict PDL regeneration. bFGF is a potent mediator for angiogenesis and plays an essential role in the formation of new blood vessels, including the differentiation of angioblasts and the subsequent formation of vascular tubules (Savona et al., 1997). Moreover, a recent report showed that tissue engineered PDL constructs incorporating human umbilical vein endothelial cells in vitro induced the formation of capillary-like structures, ALP activity and collagen deposition within the constructs (Nagai et al., 2009)

\subsection{Innervation of peripheral nerves}

Diverse functions of the nervous system have been reported in peripheral tissues. Peripheral nerves regulate DNA synthesis and proliferation of abdominal cells (Kiba et al., 1996). Denervation has been shown to suppress osteoclast activities in vertebral and mandibular bone (Imai \& Matsusue, 2002). Furthermore, alveolar nerve denervation leads to a reduction in the distribution of epithelial cell rests of Malassez (Yamashiro et al., 2000), resulting in a narrowing of the PDL width and dento-alveolar ankylosis (Fujiyama et al., 2004). Neuropeptides, such as substance $\mathrm{P}$ and calcitonin gene-related peptides that are released from axons of sensory neurons in PDL tissue (Jacobsen et al., 1998), have been shown to stimulate angiogenesis, bone remodeling (Hukkanen et al., 1993), fibroblast proliferation and collagen organization (Burssens et al., 2005). Therefore, the peripheral nervous system also plays important roles in homeostasis and the regeneration of PDL tissue.

\section{Characteristics of PDL stem cells}

A "stem cell" is capable of self-renewal and multi-lineage differentiation. In other words, stem cells possess the potential to propagate and generate additional stem cells, and can differentiate and commit to maturation along multiple lineages that produce a range of specialized cell types. Human mesenchymal stem cells (MSCs) were originally isolated in aspirates of adult bone marrow by their capacity to form clonogenic clusters of adherent fibroblast colony-forming units (Friedenstein et al., 1974). Additionally, they displayed the potential to undergo extensive proliferation and to differentiate into mesodermal lineage cells, such as adipocytes, chondrocytes and osteoblasts, both in vitro and after transfer in vivo (Pittenger et al., 1999). Human MSCs are also reported to exhibit endodermic and neuroectodermic differentiation potentials (Castro-Malaspina et al., 1980; Petersen et al., 1999; Kopen et al., 1999; Gronthos \& Simmons, 1995). In recent years, MSCs have been identified in various tissues throughout the human adult body including bone marrow, adipose tissue, placenta and muscle (Baroffio et al., 1996; Fukuchi et al., 2004; Pittenger et al., 1999; Zannettino et al., 2008).

It is considered that PDL tissue also harbors a small number of MSCs in niches that may be derived from DF cells, responsible for maintaining and regenerating periodontal tissue structure and function. The MSC population in PDL tissue has the potential to differentiate into fibroblasts, osteoblasts, and cementoblasts, which are critical cell populations to maintain and remodel periodontal tissue. In 2004, a multipotent PDL stem cell population, termed as PDLSC, was first isolated from the PDL tissue of extracted human third molar teeth (Seo et al., 2004). PDLSCs represent typical properties of MSCs, as well as unique 
properties. PDLSCs exhibit the self-renewing capacity to generate clonogenic adherent cell colonies to tissue culture plastic and resemble fibroblasts in their spindle-like shapes in vitro. Several studies have reported that PDLSCs express cell surface markers, such as STRO-1 (putative stem cell marker), CD146 (perivascular cell marker), STRO-3 (tissue nonspecific ALP), CD13, CD29 (integrin $\beta-1$ ), CD44, CD90 (Thy-1), CD105 (endoglin), CD106 (VCAM-1), and CD166 (ALCAM) (Nagatomo et al., 2006; Seo et al., 2004; Trubiani et al., 2005; Wada et al., 2009), similar to BMMSCs (Shi \& Gronthos 2003; Gronthos et al., 2007), as well as embryonic markers, including OCT-4, SSEA-1 and SSEA-4 (Trubiani et al., 2010). PDLSCs have so far been isolated from PDL heterogeneous cell populations using STRO-1 and CD146 antibodies (Seo et al., 2004), although the percentage of STRO-1-positive cells in the PDL tissue is reportedly not to be very high (STRO-1 positive cells: 1.2-7.68\%) (Nagatomo et al., 2006; Xu et al., 2009). Additionally, PDLSCs express a PDL marker, scleraxis, suggesting that PDLSCs may belong to a unique population of MSCs.

PDLSCs also possess the multipotential to differentiate in vitro into various types of cells, such as osteoblasts, adipocytes and chondrocytes, similar to BMMSCs (Gay et al., 2007). In addition to a common multipotency with BMMSCs, PDLSCs represent a unique potential to form cementum and PDL-like tissues including Sharpey's fiber-like structure in vivo, when subcutaneously transplanted into the dorsal surfaces of immunocompromised mice with a hydroxyapatite or $\beta$-TCP carrier (Seo et al., 2004). Furthermore, human PDLSCs that were transplanted into surgically created defects at the periodontal area of mandibular molars in immunocompromised rats were integrated into the PDL tissue, resulting in homing on the surfaces of alveolar bone and tooth root (Seo, et al., 2004). Swine or canine PDLSCs have also been reported to regenerate PDL tissues when transplanted into surgically created periodontal defect areas in swine or canine models (Liu et al., 2008; Park et al., 2010).

Immunomodulatory property is also known to be one of the characteristics of MSCs (Bartholomew et al., 2002). MSCs have been found to inhibit mixed lymphocyte reactions (MLR) and T-lymphocyte proliferation following mitogenic stimulation in vitro, despite expression of leucocyte antigen (HLA) major histocompatibility complex (MHC) (Bartholomew et al., 2002; Di Nicola et al., 2002), suggesting allogeneic BMMSC administration may be an appropriate stem cell therapy technique. Similarly, human and canine PDLSCs have been reported to possess the capacity to suppress immune responses and inflammatory reactions (Kim et al., 2010; Wada et al., 2009). It has been demonstrated that human PDLSCs inhibited peripheral blood mononuclear cell proliferation stimulated with mitogen or in MLR, and this inhibition was mediated by soluble factors including TGF$\beta 1$, hepatocyte growth factor (HGF) and indoleamine 2, 3-dioxygenase (IDO), known to be induced by interferon-gamma (IFN- $\gamma$ ) (Wada et al., 2009). In a swine model with experimental periodontal bone defects, the transplantation of a sheet of allogenic PDLSCs reversed the periodontitis through the low immunogenicity and immunosuppressive function possessed by PDLSCs (Ding et al., 2010).

In the first human trial report using ex-vivo-expanded primary PDL cells including PDLSCs, the cells were mixed with bone grafting material and transplanted into the intrabony defects of deep periodontal pockets of three patients. The results of the transplantations showed a significant improvement of periodontal diseases, suggesting that PDLSC transplantation could be a safe and promising treatment for clinical periodontitis (Feng et al., 2010). Furthermore, it has been reported that human PDLSCs recovered from cryopreserved human PDL tissue maintained normal PDLSC characteristics, including expression of 
STRO-1, single-colony-strain generation, multipotency and cementum/PDL-like tissue generation, providing a possible and practical clinical approach for the utilization of PDLSCs isolated from frozen PDL tissues (Seo et al., 2005).

These findings demonstrate that PDLSCs not only possess stem cell characteristics, including self-renewal, multipotency and immunomodulatory properties similar to BMMSCs, but also hold a unique potential to fabricate three-dimensional PDL tissue.

\section{PDL stem cell lines}

Because there are a small number of stem cells in PDL tissues, researchers have tried to establish immortalized PDL stem cell lines for the convenience and consistency of analyses. Several genes, such as SV 40 large T-antigen, human telomerase transcriptase, human papillomavirus 16-related E6E7, Bmi-1 and BMP4, have been transduced into mammalian PDL cells. As a consequence, clonal PDL cell lines derived from mice (Saito et al., 2002), swine (Ibi et al., 2007) and humans (Kamata et al., 2004; Fujita et al., 2005; Pi et al., 2007; Mi et al., 2011) have been developed. In addition, clonal cell lines from mouse dental follicle (DF) cells as a source of PDLSCs have also been reported (Saito et al., 2005; Luan et al., 2006). However, the multipotency in these cell lines has not been analyzed in detail. One group reported that the clonal swine PDL cell lines exhibited osteoblastic differentiation and the formation of tube-like structures (Shirai et al., 2009). Recently, our group succeeded in establishing two clonal human PDL cell lines with multipotency by transducing primary PDL cells with both SV 40 large T-antigen and human telomerase reverse transcriptase genes (Fujii et al., 2006; Fujii et al., 2008; Tomokiyo et al., 2008). These clonal cell lines had unique characteristics: Cell line 1-11 demonstrated osteoblastic and adipocytic differentiation (Fig. 1) (Fujii et al., 2008), and cell line 1-17 could differentiate into osteoblasts, chondrocytes, adipocytes and neurocytes (Fig. 2) (Tomokiyo et al., 2008).
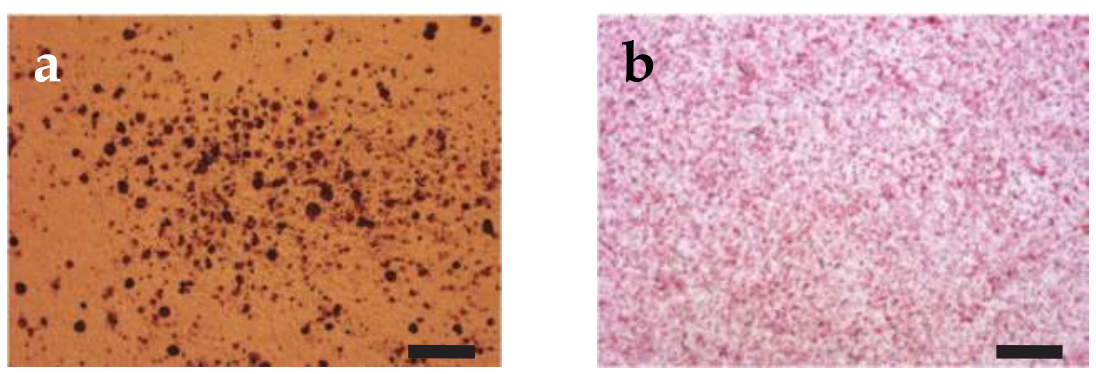

Fig. 1. Osteoblastic (a) and adiopocytic (b) differentiation of cell line 1-11. Cell line 1-11 was cultured for 4 weeks in osteoblastic induction medium. von Kossa-positive deposits (dark brown dots) were observed in (a). (b): Cell line 1-11 was cultured for 18 days in adipocytic induction medium. Oil red O-positive clusters (red) were observed. Bars: $150 \mu \mathrm{m}$.

Flow cytometric analysis demonstrated that the percentage of cells expressing CD13, CD29, CD44, CD71, CD90, CD105, and CD166 was very high in both cell lines, while the number of cells expressing an endothelial marker, CD18 and a hematopoietic marker, CD34 was low 
(data shown partially in Fig. 3). Lindroos et al. (2008) also reported the expressions of CD13, CD 29, CD44, CD90, CD105, and CD166 in human PDLSCs. Cell line 1-11 expressed other MSC markers, STRO-1 and CD146/MUC18, whereas cell line 1-17 contained STRO-1 only (data not shown), although these markers are also believed to be expressed in human and mouse PDLSCs (Seo et al., 2004; Xu et al., 2009).

On the other hand, cell line 1-17 intensely expressed ES cell marker genes, OCT-4 and Nanog, whereas cell line 1-11 expressed these markers weakly (Fig. 4). However, these expressions were reduced when the cells were cultured in osteoblast induction medium (data not shown). Furthermore, both cell lines expressed neural crest (NC)-related genes, Nestin, p75NTR and Slug at almost equivalent levels. Based on these results, these cell lines were exactly derived from NC, and cell line 1-17 may be more immature than cell line 1-11.
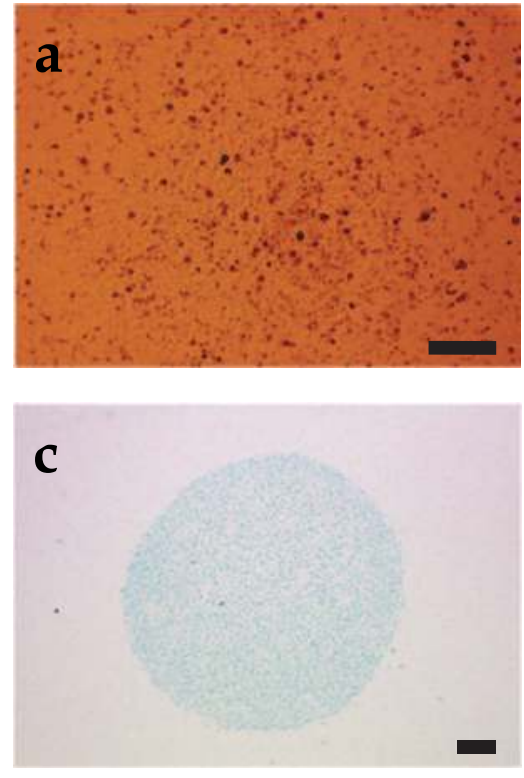
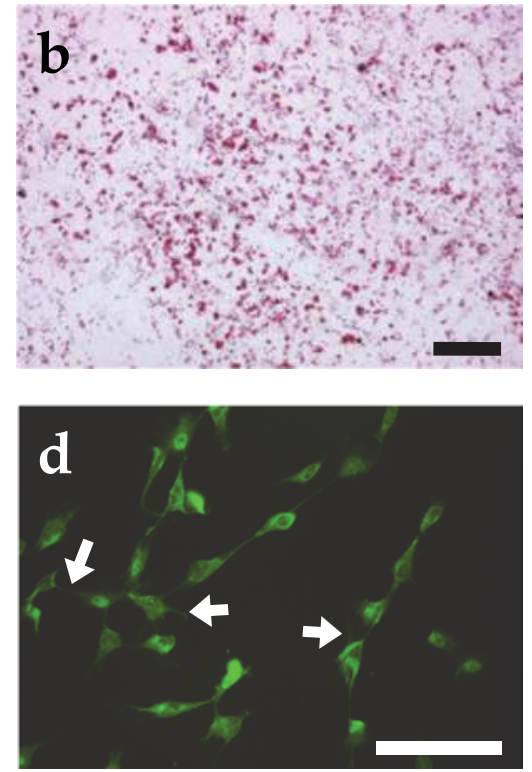

Fig. 2. Osteoblastic (a), adipocytic (b), chondrocytic (c), and neurocytic (d) differentiation of cell line 1-17. (a): Cell line 1-17 was cultured for 4 weeks in osteoblastic induction medium and then subjected to von Kossa staining. The von Kossa-positive calcified deposits (dark brown dots) were detected. (b): Cell line 1-17 was cultured for 18 days in adipocytic induction medium. Oil red O-positive clusters (red) were observed. (c): Cell line 1-17 was cultured for 4 weeks in chondrocytic induction medium and then subjected to Alcian blue staining. (d): Cell line 1-17 was cultured for 4 weeks in neurocytic induction medium and then subjected to immunocytochemical staining of human neurofilament (green). The extension of dendrite-like processes (arrows) was observed. Bars: $150 \mu \mathrm{m}$. 

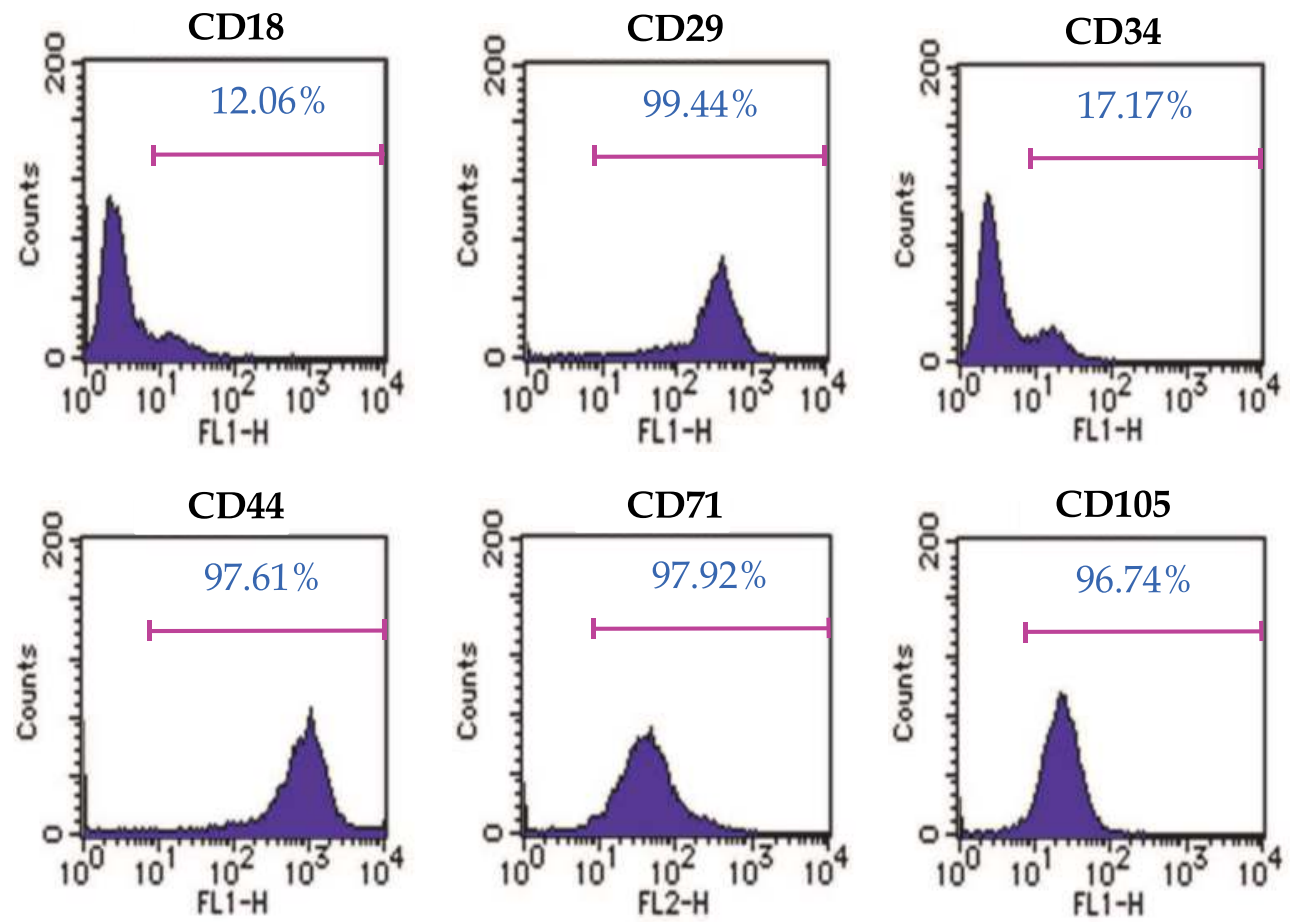

Fig. 3. Flow cytometric analysis of cell line 1-11 with antibodies reactive to the stem cellrelated surface molecules CD29, CD44, CD71 and CD105, and the endothelial and hematopoietic surface molecules, CD18 and CD34, respectively.
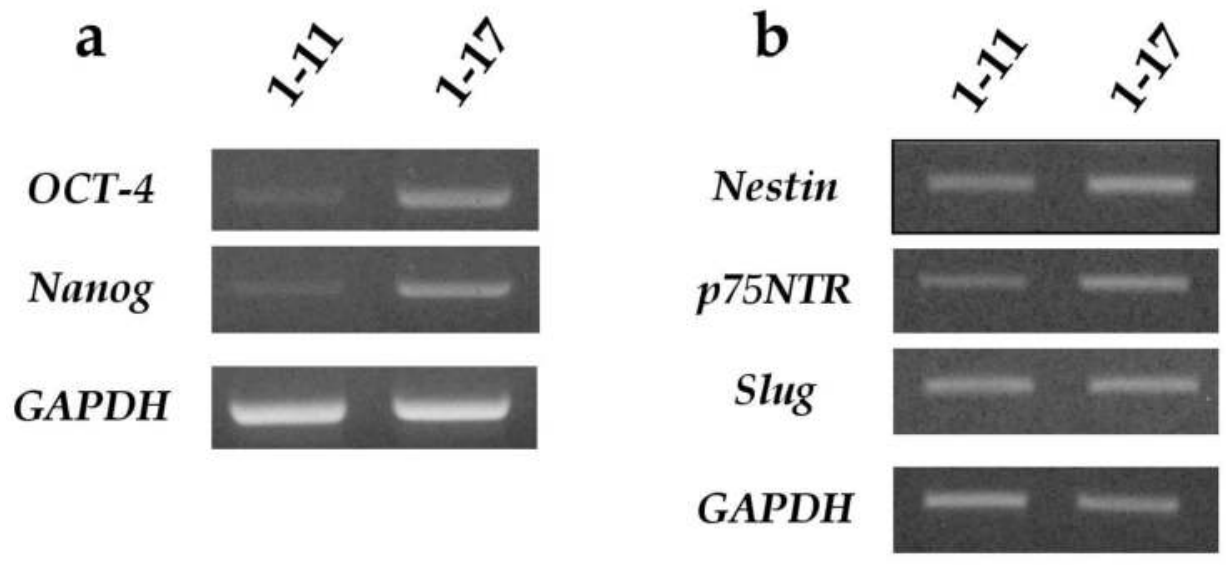

Fig. 4. Semi-quantitative RT-PCR analysis shows transcription levels of the ES cell-related pluripotency genes, OCT-4 and Nanog (a), and CNC-related genes, Nestin, p75NTR and Slug (b), in cell lines 1-11 and 1-17. 
In addition, both cell lines expressed PDL phenotype-related genes, periostin and scleraxis (Yokoi et al., 2007), at almost equivalent levels while human MSCs showed little expression of the respective genes (Fig. 5a). Immunofluorescent data demonstrated the higher expression of periostin in cell line 1-17 compared with hMSCs (Fig. 5b). These data indicate that the cell lines are obviously PDL-committed cells, exhibiting the phenotypes of stem cells.

\section{a}

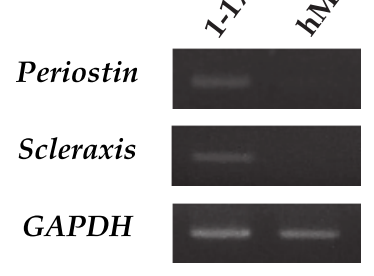

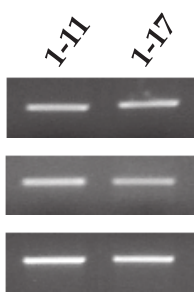

1-17

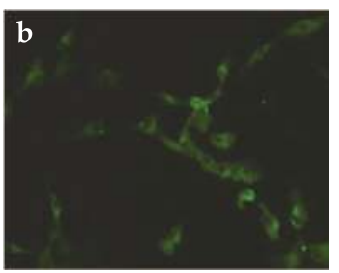

hMSC

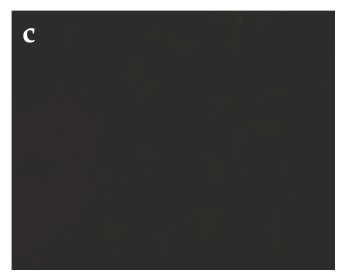

Fig. 5. Semi-quantitative RT-PCR analysis concerning the transcription of the PDL-related genes, periostin and scleraxis in cell lines 1-11 and 1-17 and in hMSCs (a).

Immunocytochemical analysis of the expression of periostin in cell line 1-17 and MSCs (b).

When cell line 1-11 was subcutaneously transplanted with $\beta$-TCP into the dorsal side of immunodeficient mice for 8 weeks, the cells fabricated PDL-like tissue including Sharpey's fiber-like structures (Fig. 6a), while cell line 1-17 did not exhibit such potential (data not shown). Furthermore, when transplanted into periodontal defects formed in immunodeficient rats for 3 weeks, cell line 1-11 homed on the surfaces of bone and root and between bone and root, namely within the ligament tissue, while cell line 1-17 was localized only within the ligament tissue (Fig. 6b, c). These observations were very similar to a previous report by Seo, et al. (2004).

1-11

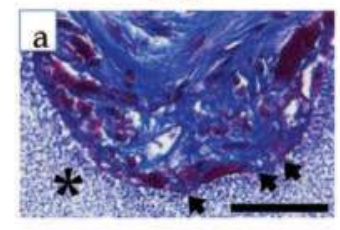

1-11

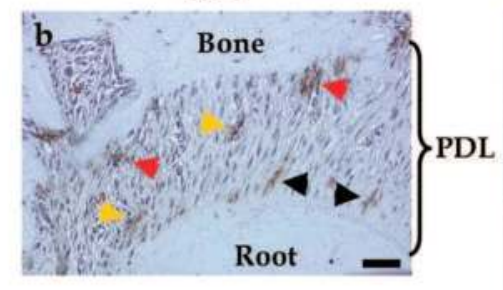

1-17

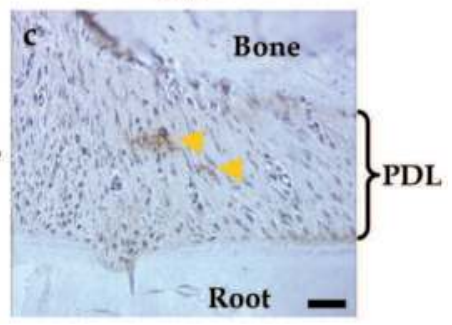

Fig.6. Trichrome staining of cell line 1-11 transplanted with $\beta$-TCP $\left(^{*}\right)$ into immunodeficient mice for 8 weeks (a). Sharpey's fiber-like structures were observed (arrows).

Immunolocalization of anti-human mitochondria-positive cells after transplantation of cell lines 1-11 (b) or 1-17 (c) into periodontal defects in immunodeficient rats. Immuno-positive cells were detected on the surface of bone (red arrows) and tooth root (black arrows) and within ligament tissue (yellow arrows). Bars: $50 \mu \mathrm{m}$. 
The treatment of two cell lines by bFGF provided intriguing results concerning osteoblastic differentiation. Although both cell lines cultured in osteoblastic differentiation medium produced calcified deposits at almost equivalent volumes, bFGF provoked these productions in cell line 1-11, while inhibited the productions in cell line 1-17 almost completely (Fig. 7).

1-11
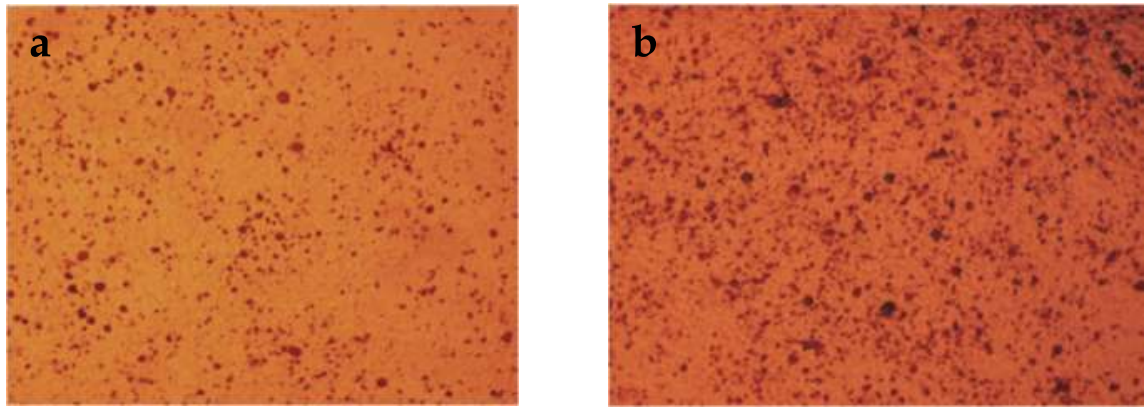

1-17
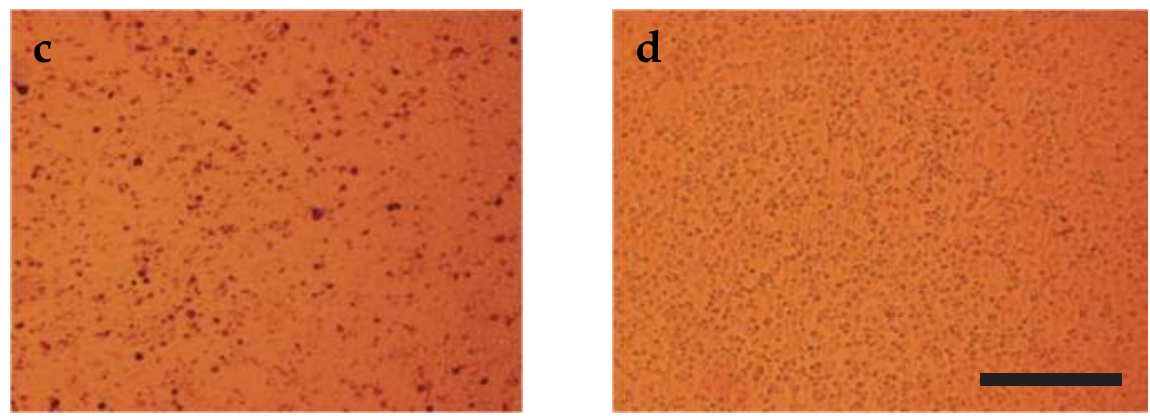

Fig. 7. von Kossa staining of cell lines 1-11 $(a, b)$ and 1-17 $(c, d)$ treated with $(b, d)$ or without $(a, c)$ bFGF in osteoblastic differentiation medium. Dark brown dots show von Kossapositive calcified deposits. Bar: $200 \mu \mathrm{m}$.

Thus, our results indicate that both cell lines met the prerequisite for PDL stem cells, and furthermore, that the differentiation stage of cell line 1-17 may be lower than that of cell line 1-11, based on the differences of multipotency and phenotypes between the lines and the transplantation analyses. These differences may be related to the expression of CD146 or the responsiveness to bFGF. Therefore, we believe that there may be distinguishing factors in these cell lines that influence the direction of stem cell differentiation within the PDL tissues.

\section{Conclusions and future directions}

Both cell lines exhibited characteristics of PDLSCs and permitted the routine analyses associated with PDLSCs. Their phenotypes, however, were somewhat different from each other. We believe that PDLSCs originate from DF cells, which stay in a niche in the PDL tissue during and after its development, and that our established cell lines would signify the existence of stem cells at various differentiation stages in the PDL tissue (Fig. 8). A differential analysis between these two clones will allow us to further reveal the mechanism of PDLSC differentiation. These results will enable elucidation of signals that direct stem 
cells including MSCs, iPS cells or ES cells toward PDL-lineage cells, as well as to identify the optimum signaling molecules and scaffolds for PDL regeneration. With the integration of these elements, the potential development of an efficient therapy for PDL regeneration is likely.

\section{Stem cells in PDL tissue}

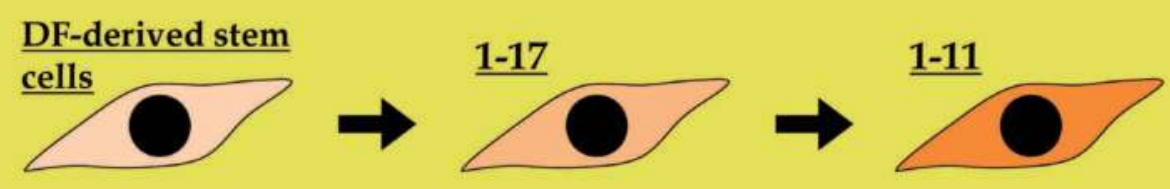

Fig. 8. Schema explaining the differentiation stages of undifferentiated cells included in the PDL tissue.

\section{Acknowledgments}

We thank Drs. Monnouchi, Kono, Koori, Yamamoto and Teramatsu for their great support in preparation of this chapter. This work was financially supported by grants-in-aid (Project Nos. 21390510, 21791942, 22390359 , 22592123, and 23659890) for scientific research from the Ministry of Education, Culture, Sports, Science and Technology (Japan).

\section{References}

Agarwal, S., Chandra, CS., Piesco, NP., et al. (1998). Infect Immun, 66: 932-937

Akman, AC., Tiğl,i RS., Gümüşderelioğlu, M., et al. (2010). J Biomed Mater Res A 92:,953-962

Asano, M., Kubota, S., Nakanishi, T., et al. (2005). Cell Commun Signal, 5: 3-11

Baroffio, A., Hamann, M., Bernheim, L., et al. (1996). Differentiation, 60: 47-57

Bartholomew, A., Sturgeon, C., Siatskas, M., et al. (2002). Exp Hematol, 30: 42-48

Beertsen, W., McCulloch, CAG. \& Sodek, J. (1997). Periodontology, 13: 20-40

Belal, MH., Watanabe, H., Ichinose, S., et al. (2006). Oral Dis, 12: 543-552

Berkovitz, BKB. \& Shore, RC. (1995). Cells of periodontal ligament, London: Mosby-Wolfe: p 9-33

Birkedal-Hansen, H. (1993). J Periodontol, 64 : 474-484

Bodine, PV., Zhao, W., Kharode, YP., et al. (2004). Mol Endocrinol, 18: 1222-1237

Bradham, DM., Igarashi, A., Potter, RL., et al. (1991). J Cell Biol, 114: 1285-1294

Brady, TA., Piesco, NP., Buckley, MJ., et al. (1998). J Dent Res, 77: 1779-1790

Bronner-Fraser M. (1993). BioEssays, 15, 221-230

Burssens, P., Steyaert, A., Forsyth, R., et al. (2005). Foot Ankle Int, 26: 832-839

Carinci, F., Piattelli, A., Guida, L., et al. (2006). Oral Dis, 12: 329-342

Carraro, JJ. (1988). Int Dent J, 38:,170-176.

Castro-Malaspina, H., Gay, RE., Resnick, G., et al. (1980). Blood, 56: 289-301

Chai, Y., Jiang, X., Ito, Y., et al. (2000). Development, 127: 1671-1679

Chen, FM., Zhao, YM., Zhang, R., \& et al. (2007). J Control Release, 121: 81-90

Chen, FM., Zhang, M. \& Wu, ZF. (2010a). Biomaterials, 31: 6279-6308

Chen, FM., Zhang, J., Zhang, M., et al. (2010b). Biomaterials, 31: 7892-7927

Cheng, H., Caterson, B. \& Yamauchi, M. (1999). Connect Tissue Res, 40: 37-47 
Cho, MI. \& Garant, PR. (2000). Periodontol 2000, 24: 9-27

Cho, MI., Lin, WL. \& Genco, RJ. (1995). J Periodontol, 66: 522-530

Chutivongse, N., Sumrejkanchanaki, P., Yongchaitrakul, T., et al. (2005). Biochem Biophys Res Commun, 336: 836-841

Dangaria, SJ., Ito, Y., Walker, C., et al. (2009). Differentiation, 78: 79-90

Dereka, XE., Markopoulou, CE., Mamalis, A., et al. (2009). Growth Factors, 27: 274-279

Di Nicola, M., Carlo-Stella, C., Magni, M., et al. (2002). Blood, 99: 3838-3843

Ding, G., Liu, Y., Wang, W., et al. (2010). Stem Cells, 28: 1829-1838

Ebendal, T. (1992). J Neurosci Res, 32: 461-470

Egelberg, J. (1967). J Periodontal Res, 1: 1-39

Feng, F., Akiyama, K., Liu, Y., et al. (2010). Oral Dis, 16: 20-28

Freeman, E. (1994) Oral histology: development, structure, and function, Ten Cate, A.R. (Ed.), pp. 276-312, Mosby, St Louis.

Friedenstein, AJ., Chailakhyan, RK., Latsinik, NV., et al. (1974). Transplantation, 17: 331-340

Fujii, S., Maeda, H., Wada, N., et al. (2006). Cell Tissue Res, 324: 117-125

Fujii, S., Maeda, H., Wada, N., et al. (2008). J Cell Physiol, 215: 743-749

Fujii, S., Maeda, H., Tomokiyo, A., et al. (2010). Cell Tissue Res, 342: 233-242

Fujita, T., Otsuka-Tanaka, Y., Tahara, H., et al. (2005). J Oral Sci, 47: 177-184

Fujita, T., Shiba, H., Van Dyke, TE., et al. (2004). Cell Biol Int, 28: 281-286

Fujiyama, K., Yamashiro, T., Fukunaga, T., et al. (2004). J Dent Res, 83: 625-629

Fukuchi, Y., Nakajima, H., Sugiyama, D., et al. (2004). Stem Cells, 22: 649-658

Fukui, N., Sato, T., Kuboki, Y., et al. (2008). Biomed Mater Eng 18:25-33

Gay, IC., Chen, S. \& MacDougall, M. (2007). Orthod Craniofac Res, 10: 149-160

Giannobile, WV., Ryan, S., Shih, MS., et al. (1998). J Periodontol, 69: 129-137

Gospodarowicz, D., Neufeld, G. \& Schweigerer, L. (1986). Mol Cell Endocrinol, 46: 187-204

Gronthos, S. \& Simmons, PJ. (1995). Blood, 85: 929-940

Gronthos, S., Mankani, M., Brahim, J., et al. (2000). Proc Natl Acad Sci U S A, 97: 13625-13630

Gronthos, S., Fitter, S., Diamond, P., et al. (2007). Stem Cells Dev, 16: 953-963

Hakki, SS., Hakki, EE. \& Nohutcu, RM. (2009). J Periodontal Res, 44: 794-802

Häkkinen, L., Oksala, O., Salo, T., et al. (1993). J Histochem Cytochem, 41: 1689-1699

Hammarstrom, L. (1997). Ciba Found Symp, 205: 246-255

Hasegawa, T., Yoshimura, Y., Kikuiri, T., et al. (2002). J Periodontal Res, 37: 405-411

Heng, NH., N'Guessan, PD., Kleber, BM., et al. (2007). J Periodontol, 78: 2369-2379

Heo, JS., Lee, SY. \& Lee, JC. (2010). Mol Cells, 30: 449-454

Hukkanen, M., Konttinen, YT., Santavirta, S., et al. (1993). Neuroscience, 54: 969-979

Ibi, M., Ishisaki, A., Yamamoto, M., et al. (2007). Arch Oral Biol, 52: 1002-1008

Imai, S. \& Matsusue, Y. (2002). Microsc Res Tech, 58: 61-69

Inanç, B., Eser Elçin, A., Koç, A., et al. (2007). J Biomed Mater Res A, 82: 917-926

Jacobsen, EB., Fristad, I. \& Heyeraas, KJ. (1998). Acta Odontol Scand, 56: 220-228

Kamata, N., Fujimoto, R., Tomonari, M., et al. (2004). J Oral Pathol Med, 33: 417-423

Kanzaki, H., Chiba, M., Shimizu, Y., et al. (2001). J Dent Res, 80: 887-891

Kato, C., Kojima, T., Komaki, M., et al. (2005). Biochem Biophys Res Commun, 326: 147-153

Kato, M., Patel, MS., Levasseur, R., et al. (2002). J Cell Biol, 157: 303-314

Kawaguchi, H., Hirachi, A., Hasegawa, N., et al. (2004). J Periodontol, 75: 1281-1287

Kiba, T., Tanaka, K., Numata, K., et al. (1996). Gastroenterology, 110: 885-893

Kim, HS., Kim, KH., Kim, SH., et al. (2010). J Periodontal Implant Sci, 40: 265-270

Kim, IY., Seo, SJ., Moon, HS., et al. (2008). Biotechnol Adv, 26: 1-21

Kim, TG., Wikesjö, UM., Cho, KS., et al. (2009). J Clin Periodontol, 36: 589-597

Kinoshita, A., Oda, S., Takahashi, K., et al. (1997). J Periodontol, 68: 103-109 
King, GN., King, N. \& Hughes, FJ. (1998). J Periodontol, 69: 561-570

Kitamura, M., Akamatsu, M., Machigashira, M., et al. (2011). J Dent Res, 90: 35-40

Kopen, GC., Prockop, DJ. \& Phinney, DG. (1999). Proc Natl Acad Sci U S A, 96: 10711-10716

Kwon, DH., Bennett, W., Herberg, S., et al. (2010). J Clin Periodontol, 37: 390-397

Lamont, RJ. \& Jenkinson, HF. (1998). Microbiol Mol Biol Rev, 62: 1244-1263

Langer, R. \& Vacanti, JP. (1993). Science, 260: 920-926

Le Douarin. NM., Ziller, C. \& Coul, G. (1993). Dev Biol, 159: 24-49

Lee, CH., Moioli, EK. \& Mao, JJ. (2006). Conf Proc IEEE Eng Med Biol, 1: 775-778

Lekic, P. \& McCulloch, CA. (1996). Anat Rec, 245: 327-341

Lekic, P., Rojas, J., Birek, C., et al. (2001). J Periodontal Res, 36: 71-79

Li, H., Bartold, PM., Young, WG., et al. (2001). J Bone Miner Res, 16: 1068-1076

Lindemann, RA., Economou, JS. \& Rothermel, H. (1988). J Dent Res, 67: 1131-1135

Lindroos, B., Mäenpää, K., Ylikomi, T., et al. (2008). Biochem Biophys Res Commun, 368: 329-335

Ling, E. \& Robinson, DS. (2002). Clin Exp Allergy, 32: 175-178

Liu, Y., Zheng, Y., Ding, G., et al. (2008). Stem Cells, 26: 1065-1073

Logan, CY. \& Nusse, R. (2004). Annu. Rev. Cell Dev. Biol, 20: 781-810

Luan, X., Ito, Y., Dangaria, S., et al. (2006). Stem Cells Dev, 15: 595-608

Luan, X., Dangaria, S., Ito, Y., et al. (2009). J Dent Res, 88: 781-791

Lukinmaa, PL. \& Waltimo, J. (1992). J Dent Res, 71: 391-397

MacNeil, RL., Berry, JE., Strayhorn, CL., et al. (1998). Arch Oral Biol, 43: 779-787

McCulloch, CA., Nemeth, E., Lowenberg, B., et al. (1987). Anat Rec, 219: 233-242

McCulloch, CA, \& Bordin, S. (1991). J Periodontal Res, 26: 144-154

Melcher, AH. (1976). J Periodontol, 47: 256-260

Melcher, AH. (1984). Michigan: University of Michigan Press, pp. 1-15

Mi, HW., Lee, MC., Fu, E., et al. (2011). Gene Ther, in press

Miura, M., Gronthos, S., Zhao, M., et al. (2003). Proc Natl Acad Sci U S A, 100: 5807-5812

Mizutani, S., Tsuboi, T., Tazoe, M., et al. (2003). Oral Dis, 9: 210-217

Murakami, S., Takayama, S., Kitamura, M., et al. (2003). J Periodontal Res, 38: 97-103

Nagai, N., Hirakawa, A., Otani, N., t al. (2009). Cells Tissues Organs, 190: 303-312

Nagatomo, K., Komaki, M., Sekiya, I., et al. (2006). J Periodontal Res, 41: 303-310

Nakahara, T., Nakamura, T., Kobayashi, E., et al. (2003). Tissue Eng, 9: 153-162

Nemoto, E., Koshikawa, Y., Kanaya, S., et al. (2009). Bone, 44: 805-812

Nevins, M., Giannobile, WV., McGuire, MK., et al. (2005). J Periodontol, 76: 2205-2215

Oyama, T., Matsushita, K., Sakuta, T., et al. (2007). J Periodont Res, 42: 53-61

Palmon, A., Roos, H., Reichenberg, E., et al. (2001). J Periodontal Res, 36: 65-70

Pang, EK., Paik, JW., Kim, SK., et al. (2005). J Periodontol, 76: 1526-1533

Park, JY., Jeon, SH. \& Choung, PH. (2010). Cell Transplant, in press.

Petersen, BE., Bowen, WC., Patrene, KD., et al. (1999). Science, 284: 1168-1170

Pi, SH., Lee, SK., Hwang, YS., et al. (2007). J Periodontal Res, 42: 104-113

Pittenger, MF., Mackay, AM., Beck, SC., et al. (1999). Science, 284: 143-147

Quintero, JC., Piesco, NP., Langkamp, HH., et al. (1995). J Dent Res, 74: 1802-181

Rajshankar, D., McCulloch, CA., Tenenbaum, HC., et al. (1998). Cell Tissue Res, 294: 475-483

Ripamonti, U., Parak, R. \& Petit, JC. (2009). J Periodontal Res, 44: 81-87

Roberts, WE., Mozsary, PG. \& Klingler, E. (1982). Am J Anat, 165: 373-384

Rungsiyanont, S., Dhanesuan, N., Swasdison, S., et al. (2011). J Biomater Appl, in press.

Saito, M., Handa, K., Kiyono, T., et al. (2005). J Bone Miner Res, 20: 50-57

Saito, Y., Yoshizawa, T., Takizawa, F., et al. (2002). J Cell Sci, 115: 4191-4200

Savona, C., Javerzat, S., Perollet, C., et al. (1997). Rev Prat, 47: 2239-2243

Selvig, KA., Sorensen, RG., Wozney, JM., et al. (2002). J Periodontol, 73: 1020-1029 
Seo, BM., Miura, M., Gronthos, S., et al. (2004). Lancet, 364: 149-155

Seo, BM., Miura, M., Sonoyama, W., et al. (2005). J Dent Res, 84: 907-912

Shi, S. \& Gronthos, S. (2003). J Bone Miner Res, 18: 696-704

Shimabukuro, Y., Ichikawa, T., Terashima, Y., et al. (2008). Matrix Biol, 27: 232-241

Shirai, K., Ishisaki, A., Kaku, T., et al. (2009). J Periodontal Res, 44: 238-247

Si, X. \& Liu, Z. (2001). Zhonghua Kou Qiang Yi Xue Za Zhi, 36: 23-26

Sodek, J. \& Limeback, HF. (1979). J Biol Chem, 254: 10496-10502

Sonoyama, W., Liu, Y., Fang, D., et al. (2006). PLoS One, 1:e79

Sun, W., Chu, C., Wang, J., et al. (2007). J Mater Sci Mater Med, 18: 677-683

Takayama, S., Murakami, S., Miki, Y., et al. (1997). J Periodontal Res, 32: 667-675

Takeda, K., Shiba, H., Mizuno, N., et al. (2005). Tissue Eng, 11: 1618-1629

Takeda, K., Sakai, N., Shiba, H., et al. (2011). Tissue Eng Part A, in press

Takeuchi, H., Kubota, S., Murakashi, E., et al. (2009). J Periodontal Res, 44: 161-169

Ten Cate, AR. (2008). Oral histology, development, structure, and function, St. Louis: Mosby. pp. 239-267

Terashima, Y., Shimabukuro, Y., Terashima, H., et al. (2008). J Cell Physiol, 216: 640-650

Tobita, M., Uysal, AC., Ogawa, R., et al. (2008). Tissue Eng Part A, 14: 945-953

Tomokiyo, A., Maeda, H., Fujii, S., et al. (2008). Differentiation, 76: 337-347

Trubiani, O., Di Primio, R., Traini, T., et al. (2005). Int J Immunopathol Pharmacol, 18: 213-221

Trubiani, O., Orsini, G., Zini, N., et al. (2008). J Biomed Mater Res A, 87: 986-993

Trubiani, O., Zalzal, SF., Paganelli, R., et al. (2010). J Cell Physiol, 225: 123-131

Tsuboi, Y., Nakanishi, T., Takano-Yamamoto, T., et al. (2001). I Dent Res, 80: 881-886

Wada, N., Maeda, H., Tanabe, K., et al. (2001). J Periodontal Res, 36: 56-63

Wada, N., Maeda, H., Yoshimine, Y., et al. (2004). Bone, 35: 629-635

Wada, N., Menicanin, D., Shi, S., et al. (2009). J Cell Physiol, 219: 667-676

Wikesjö, UM., Sorensen, RG., Kinoshita, A., et al. (2004). J Clin Periodontol, 31: 662-670

Wolfman, NM., Hattersley, G., Cox, K., et al. (1997). J Clin Invest, 100: 321-330

Worapamorn, W., Haase, HR., Li, H., et al. (2001). J Cell Physiol, 186: 448-456

Xiang, J., Li, C., Dong, W., et al. (2009). J Periodont Res, 44: 784-793

Xu, J., Wang, W., Kapila, Y., et al. (2009). Stem Cells Dev, 18: 487-496

Yamada, S., Murakami, S., Matoba, R., et al. (2001). Gene, 275: 279-286

Yamada, Y., Ueda, M., Hibi, H., et al. (2006). Int J Periodontics Restorative Dent, 26: 363-369

Yamashiro, T., Fujiyama, K., Fujiyoshi, Y., et al. (2000). Bone, 26: 663-669

Yeo, YJ., Jeon, DW., Kim, CS., et al. (2005). J Biomed Mater Res B Appl Biomater, 72: 86-93

Yokoi, T., Saito, M., Kiyono, T., et al. (2007). Cell Tissue Res, 330: 133-145

Zannettino, AC., Paton, S., Arthur, A., et al. (2008). J Cell Physiol, 214: 413-421

Zhang, YF., Cheng, XR., Chen, Y., et al. (2007). J Biomater Appl, 21: 333-349 


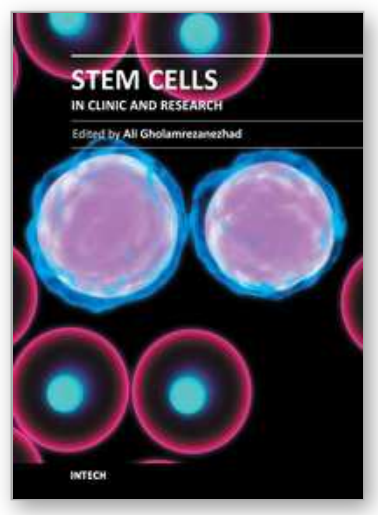

\author{
Stem Cells in Clinic and Research \\ Edited by Dr. Ali Gholamrezanezhad
}

ISBN 978-953-307-797-0

Hard cover, 804 pages

Publisher InTech

Published online 23, August, 2011

Published in print edition August, 2011

Based on our current understanding of cell biology and strong supporting evidence from previous experiences, different types of human stem cell populations are capable of undergoing differentiation or trans-differentiation into functionally and biologically active cells for use in therapeutic purposes. So far, progress regarding the use of both in vitro and in vivo regenerative medicine models already offers hope for the application of different types of stem cells as a powerful new therapeutic option to treat different diseases that were previously considered to be untreatable. Remarkable achievements in cell biology resulting in the isolation and characterization of various stem cells and progenitor cells has increased the expectation for the development of a new approach to the treatment of genetic and developmental human diseases. Due to the fact that currently stem cells and umbilical cord banks are so strictly defined and available, it seems that this mission is investigationally more practical than in the past. On the other hand, studies performed on stem cells, targeting their conversion into functionally mature tissue, are not necessarily seeking to result in the clinical application of the differentiated cells; In fact, still one of the important goals of these studies is to get acquainted with the natural process of development of mature cells from their immature progenitors during the embryonic period onwards, which can produce valuable results as knowledge of the developmental processes during embryogenesis. For example, the cellular and molecular mechanisms leading to mature and adult cells developmental abnormalities are relatively unknown. This lack of understanding stems from the lack of a good model system to study cell development and differentiation. Hence, the knowledge reached through these studies can prove to be a breakthrough in preventing developmental disorders. Meanwhile, many researchers conduct these studies to understand the molecular and cellular basis of cancer development. The fact that cancer is one of the leading causes of death throughout the world, highlights the importance of these researches in the fields of biology and medicine.

\title{
How to reference
}

In order to correctly reference this scholarly work, feel free to copy and paste the following:

Hidefumi Maeda, Naohisa Wada, Shinsuke Fujii, Atsushi Tomokiyo and Akifumi Akamine (2011). Periodontal Ligament Stem Cells, Stem Cells in Clinic and Research, Dr. Ali Gholamrezanezhad (Ed.), ISBN: 978-953-307797-0, InTech, Available from: http://www.intechopen.com/books/stem-cells-in-clinic-and-research/periodontalligament-stem-cells

\section{INTECH}

open science | open minds 


\section{InTech Europe}

University Campus STeP Ri

Slavka Krautzeka 83/A

51000 Rijeka, Croatia

Phone: +385 (51) 770447

Fax: +385 (51) 686166

www.intechopen.com

\section{InTech China}

Unit 405, Office Block, Hotel Equatorial Shanghai

No.65, Yan An Road (West), Shanghai, 200040, China

中国上海市延安西路65号上海国际贵都大饭店办公楼 405 单元

Phone: +86-21-62489820

Fax: $+86-21-62489821$ 
(C) 2011 The Author(s). Licensee IntechOpen. This chapter is distributed under the terms of the Creative Commons Attribution-NonCommercialShareAlike-3.0 License, which permits use, distribution and reproduction for non-commercial purposes, provided the original is properly cited and derivative works building on this content are distributed under the same license. 